\title{
Literature Review: Meningkatkan Kepuasan Pelanggan Di Bengkel Resmi Menggunakan Sistem Manajemen Pelanggan Elektronik
}

\author{
Andhika Octa \\ Sistem Informasi, Fakultas Ilmu Komputer \\ Universitas Pembangunan Nasional Veteran Jakarta \\ Jalan RS Fatmawati No. 1, Pondok Labu, Jakarta Selatan, DKI Jakarta 12450 \\ andyocta@upnvj.ac.id
}

\begin{abstract}
Abstrak. Kemajuan teknologi memberikan kemudahan di berbagai sektor, termasuk ke dalam sektor bisnis atau usaha. Bila dulu berkomunikasi dengan para pelanggan melalui saluran telepon atau mendatangi secara langsung dengan cara door to door. Kemajuan teknologi internet, memberikan terobosan terbaru khususnya dalam perkembangan Sistem Manajemen Pelanggan. Perusahaan dapat memanfaatkan teknologi internet untuk mendekatkan diri dengan pelanggan secara langsung selama 24 jam dalam 7 hari seminggu dengan cepat dan mudah melalui Sistem Manajemen Pelanggan secara Elektronik. Manajemen Pelanggan Elektronik bukan sekedar sebuah sistem yang dapat memudahkan pelaku bisnis dalam menganalisa kebutuhan ataupun melakukan interaksi langsung kepada pelanggannya, melainkan menjadi kunci penting bagi pelaku bisnis yang berorientasi kepada pelanggan untuk meningkatkan kepuasan para pelanggannya. Penelitian ini ditujukan untuk melakukan kajian terhadap literatur maupun hasil penelitian serta artikel yang berhubungan dengan penerapan Sistem Manajemen Pelanggan Elektronik atau dikenal dengan nama lain e-CRM yang diterapkan pada bengkel resmi. Hasil kajian yang berasal dari jurnal-jurnal yang berkaitan dengan e-CRM di bengkel resmi dilakukan analisis yang lebih dalam lagi.
\end{abstract}

Keywords: e-CRM, CRM, customer relationship management, electronic customer relationship management, tingkat kepuasan pelanggan, $e$-business, sistem manajemen pelanggan, sistem manajemen elektronik

\section{Pendahuluan}

Dunia bisnis akan terus berkembang seiring perkembangan teknologi. Hadirnya teknologi internet memberikan kesempatan bagi dunia bisnis untuk terus berkembang lebih luas lagi. Internet menjadi sarana atau media yang tepat untuk mendekatkan diri dengan para pelanggan secara langsung, mudah, dan dapat menjangkau pelanggan yang berada di seluruh dunia. Melalui sistem manajemen pelanggan elektronik atau e-CRM (Electronic Customer Relationship Management), para pebisnis bisa mendapatkan beragam informasi mengenai pelanggan di dalamnya dan perlu dijaga dengan baik. Persaingan di dunia usaha sangat ketat, sehingga menjaga pelanggan agar tidak beralih ke kompetitor sangat perlu dilakukan dengan baik. Menurut Chaffey (2009) [1], bila perusahaan dapat mempertahankan pelanggan setianya, maka perusahaan akan mendapatkan keuntungan yang lebih cepat bila dibandingkan melakukan bisnis secara konvensional. Hal ini berarti mengeluarkan sedikit biaya untuk memberikan pelayanan kepada pelanggan.

Jumlah merek kendaraan terus bertambah, persaingan untuk merebut para pelanggan pun tidak dapat dihindari. Para pelaku dunia otomotif harus terus melakukan inovasi untuk menghasilkan produk-produk yang inovatif dan bersaing untuk memuncaki persaingan di pasar otomotif. Berdasarkan data yang dikeluarkan oleh AISI (Asosiasi Industri Sepeda Motor Indonesia) [2] mencatatkan penjualan sepeda motor meningkat hingga 1.100.950 unit sepanjang 2019 yang mengalami peningkatan 19,4 persen dari tahun sebelumnya yang hanya terjual 922.123 unit di tahun 2018. Sedangkan untuk kendaraan roda empat, data Gabungan Industri Kendaraan Bermotor Indonesia atau biasa disebut GAIKINDO [3] mencatat terjadi perkembangan yang positif di tahun 2019 tercatat 660.286 unit mobil berhasil terjual. Bila dilihat dari hal tersebut, maka persaingan antarprodusen kendaraan baik roda dua maupun empat terbilang cukup ketat.

Sebuah agensi pemasaran yang cukup terkenal di Amerika Serikat, J.D. Power [4] mengungkapkan bahwa ada beberapa poin penting yang bisa dimanfaatkan oleh industri otomotif di Indonesia untuk meningkatkan kepuasan pelanggannya, seperti:

ISSN : 2655-139X (ONLINE)

ISSN : 0216-4221 (PRINT) 
1. Memanfaatkan saluran digital untuk membuat penjadwalan secara rutin melalui aplikasi mobile atau website yang bisa diakses secara langsung oleh pelanggan.

2. Terjadinya peningkatan jumlah pelanggan yang datang untuk melakukan perawatan rutin kendaraan di bengkel resmi.

3. Terjadinya peningkatan transaksi penggantian suku cadang resmi saat pelanggan melakukan perawatan rutin.

4. Mengoptimalkan dan bekerja secara efisien dan cepat saat memberikan pelayanan perawatan rutin kendaraan dari awal hingga akhir.

Layanan purnajual seperti pelayanan bengkel resmi dapat menjangkau dan melayani pelanggan secara langsung tanpa melalui perantara. Manajemen bengkel dapat memantau apa saja kebutuhan ataupun keluh kesan pelanggan saat di bengkel resmi secara nyata dan tanpa rekayasa. Ketika ada masalah, diharapkan pihak manajemen bengkel dapat memberikan solusi dengan tepat dan cepat. Agar memudahkan pihak manajemen bengkel memantau tingkat kepuasan pelanggannya bisa memanfaatkan sistem manajemen pelanggan elektronik atau biasa disebut dengan eCRM. Melalui sistem e-CRM, pihak manajemen dapat mengumpulkan beragam informasi milik pelanggan. Pada pembahasan ini, penulis ingin memberikan informasi mengenai sistem manajemen pelanggan berbasis elektronik yang dimanfaatkan pada sektor otomotif khususnya di bengkel resmi.

\section{Kajian Literatur}

\subsection{CRM vs e-CRM}

CRM atau Customer Relationship Management merupakan sebuah bentuk strategi yang dijalankan oleh perusahaan untuk mempertahankan pelanggan yang lama dan berupaya untuk meningkatkan loyalitas pelanggan, dan mendapatkan pelanggan baru bagi perusahaan. Secara teknologi, CRM merupakan sistem yang di dalamnya berisikan informasi atau data pelanggan yang terintegrasi dengan proses bisnis perusahaan untuk memudahkan pihak manajemen melakukan analisa terhadap kepuasan pelanggannya terhadap produk, pelayanan pelanggan, hingga layanan purnajual yang diberikan oleh perusahaan ke pelanggannya. Hal ini akan memberikan informasi yang tepat terhadap kebutuhan serta kebiasaan para pelanggan yang dapat dipantau secara kontinu oleh perusahaan.

Menurut Kurniawan (2009) dalam Teti Wijayanti dan Ahmad Dahlan (2011) [5], CRM dibagi ke dalam tiga klasifikasi, yakni: pertama, Operasional CRM yang merupakan bagian terdepan dari perusahaan. Di bagian ini, memiliki fungsi berinteraksi secara langsung dengan para pelanggan, termasuk proses otomatisasi dari keseluruhan bisnis proses, seperti otomatisasi penjualan, pemasaran, dan termasuk pelayanan. Bentuk dari klasifikasi pertama ini adalah aplikasi berbasis web. Bagian kedua adalah Analitis CRM. Pada bagian kedua ini merupakan bagian back office atau berada di belakang meja yang berfungsi untuk menganalisa kebutuhan pelanggan, apa yang pelanggan butuhkan, apa yang pelanggan inginkan dari pelayanan yang diberikan oleh perusahaan, kebiasaan para pelanggan, hingga memantau tren pasar yang sedang berlangsung. Di bagian terakhir, disebut sebagai kolaboratif CRM. Klasifikasi ketiga ini termasuk di dalamnya, kolaborasi antara promosi dan komunitas yang diperuntukan untuk menjalin interaksi secara personal antara perusahaan dengan pelanggan. Fungsi utama dari bagian ini adalah menyebarkan informasi, baik ke pelanggan yang memiliki loyalitas tinggi, maupun ke pelanggan yang belum memiliki hal tersebut. Diharapkan pada bagian klasifikasi ketiga ini, dibutuhkan pemahaman atau memiliki kesadaran dimana pelanggan yang memiliki loyalitas tinggi dapat menarik perhatian para calon konsumen lainnya. 
Ada tiga komponen penting CRM (Paul 2001; Khalaf et al., 2013) [6]:

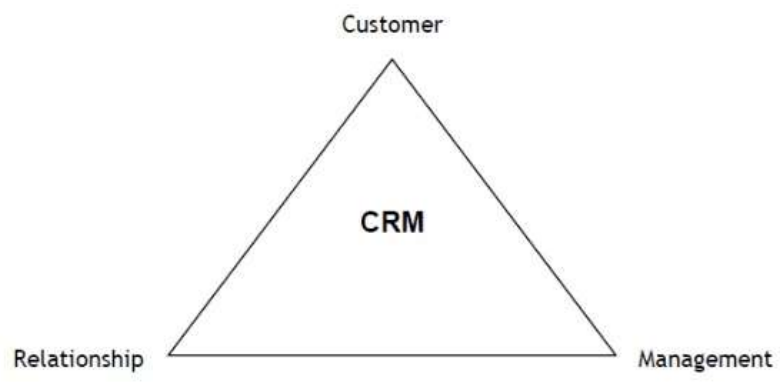

Gambar 1. Komponen Penting CRM

Pelanggan atau customer merupakan aset penting bagi perusahaan. Perusahaan dapat menjadi maju atau mundur tergantung dari para pelanggannya. Maka dari itu penggunaan CRM penting sekali untuk dimanfaatkan mengolah informasi yang didapatkan secara langsung dari pelanggan.

Hubungan atau relationship merupakan sebuah interaksi yang terjadi antara perusahaan dengan para pelanggannya. Hal ini bisa dalam bentuk hubungan jangka panjang maupun pendek atau sesekali saja maupun berkelanjutan.

Pengelolaan atau management yang berarti CRM tidak hanya penting untuk digunakan pada bagian pemasaran saja. Melainkan informasi yang diperoleh dapat dijadikan sebagai acuan bagi perusahaan untuk memperhatikan perkembangan pasar di masa mendatang dan mengubah strategi, budaya, serta proses bisnis perusahaan secara keseluruhan.

Menurut Kalakota dan Robinson (2001) [7] ada beberapa fase pelanggan yang ada di dalam CRM:

1. Mendapatkan Pelanggan Baru. Pada fase ini CRM digunakan untuk mencari pelanggan baru. Perusahaan akan melakukan berbagai program promosi produk hasil inovasi terbaru yang didukung pelayanan yang baik untuk menarik pelanggan baru.

2. Meningkatkan Keuntungan yang ada. Di fase ini, perusahaan melakukan pendekatan yang lebih personal kepada pelanggan yang ada dengan memperhatikan kebutuhan mereka melalui cara cross selling dan upselling. Cross selling berarti perusahaan memberikan penawaran produk sebagai pelengkap dari yang sudah dimiliki oleh pelanggan. Sedangkan up-selling berarti perusahaan melakukan penawaran produk yang sudah dimiliki oleh pelanggan namun dengan kualitas yang lebih baik lagi.

3. Mempertahankan Pelanggan. Tahap terakhir, yakni perusahaan mempertahankan pelanggan yang ada melalui mengevaluasi tingkat kepuasan pelanggan.

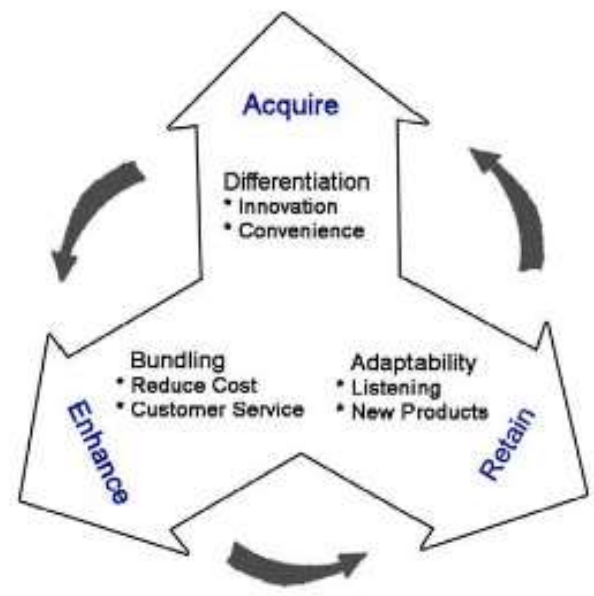

Gambar 2. Tiga Fase Pelanggan di CRM

Buttle (2007) [8] menuturkan bahwa kunci penting penerapan CRM adalah sebagai berikut:

1. CRM dapat membedakan pelanggan,

2. CRM dapat membedakan penawaran,

ISSN : 2655-139X (ONLINE)

ISSN : 0216-4221 (PRINT) 
3. CRM dapat mempertahankan pelanggan yang sudah ada,

4. CRM dapat meningkatkan keuntungan bagi bisnis,

5. CRM dapat meningkatkan loyalitas pelanggan yang sudah ada.

Perkembangan teknologi yang terjadi memberikan perubahan dalam penerapan CRM menjadi e-CRM. Sistem CRM tradisionil yang sebelumnya hanya berada mengadalkan teknologi penggunaan fax maupun jalur telepon, sekarang telah berubah dengan memanfaatkan teknologi internet. Penerapan e-CRM diaplikasikan ke dalam aplikasi yang berbasis teknologi internet, seperti email, website, chat room, dan beragam media lainnya yang dapat diterapkan dalam sistem CRM tradisionil. e-CRM bisa dijadikan sebagai strategi perusahaan yang mengandalkan teknologi jaringan atau internet melalui sistem yang dirancang terintegrasi dengan bagian pemasaran, penjualan hingga layanan pelanggan. Menurut Ab Hamid dan McGrath (2005) [9], ada 12 dimensi dari e-CRM, seperti:

1. Kualitas Informasi

2. Kemudahan Bernavigasi

3. Kualitas Pelayanan Pelanggan

4. Pemenuhan

5. Mengintegrasikan Saluran Pemasaran

6. Komunitas Online

7. Penghargaan

8. Tingkat Personalisasi

9. Keamanan Situs

10. Layanan Bernilai Tambah

11. Kepercayaan yang dirasakan

12. Harga yang Menarik

Menurut Turban et al. (2004) [10], Cakupan e-CRM memiliki tiga level penting, seperti:

1. Pelayanan Dasar

2. Pelayanan yang Berorientasi Pelanggan

3. Pelayanan Bernilai Tambah

\subsection{Kepuasan Pelanggan}

Bentuk penilaian dari pelanggan terhadap produk maupun pelayan yang diberikan oleh perusahaan sesuai atau tidak dengan harapan mereka disebut sebagai kepuasan pelanggan. Ada beberapa indikator kepuasan pelanggan menurut Kottler (Pratiwi 2010:32) [11], seperti:

1. Pelanggan akan membeli produk secara terus-menerus atau berulang-ulang.

2. Pelanggan memberikan rekomendasi kepada orang lain.

3. Pelanggan akan cenderung berkurang perhatiannya kepada produk-produk kompetitor.

4. Pelanggan akan membeli produk yang berbeda meskipun dari satu perusahaan.

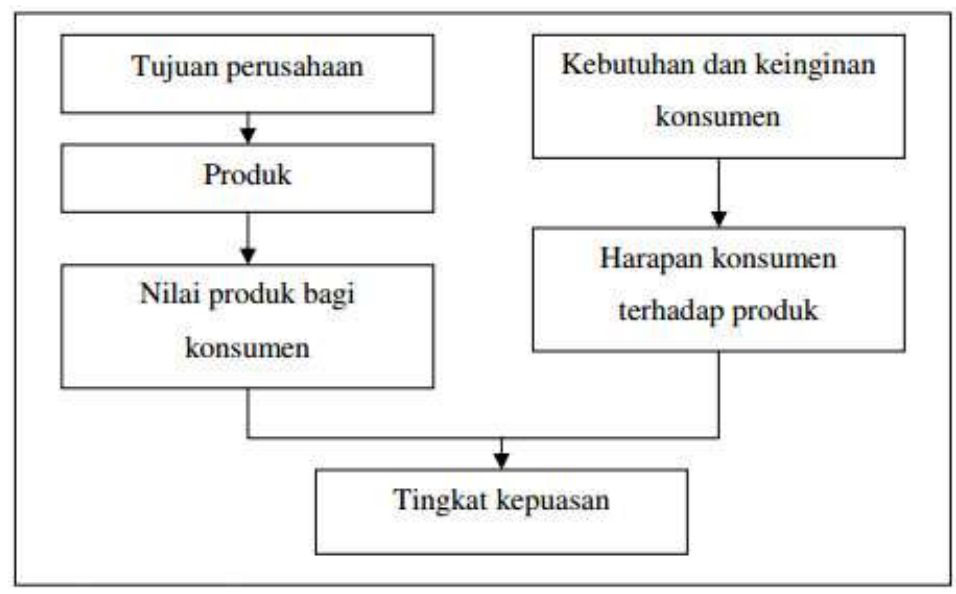

ISSN : 2655-139X (ONLINE)

ISSN : 0216-4221 (PRINT) 
Gambar 3. Kepuasan Pelanggan

Berdasarkan gambar 3, terlihat bahwa tingkat kepuasan pelanggan berasal dari keyakinan konsumen terhadap produk atas jasa yang diberikan oleh para pelaku usaha atau bisnis sesuai dengan harapan mereka.

\subsection{SERVQUAL}

SERVQUAL atau service quality merupakan bentuk pengukuran terhadap kualitas pelayanan dimana membandingkan sebelum dan sesudah diberikan pelayanan, dan tanggapan pelanggan terhadap pelayanan yang diberikan. Menurut Zeithaml dan Bitner (2003) [12], ada lima aspek kualitas pelayanan, seperti:

1. Tangibles (Berwujud)

2. Reliability (Keandalan)

3. Responsiveness (Cepat Tanggap)

4. Assurance (Kepastian)

5. Empathy (Empati)

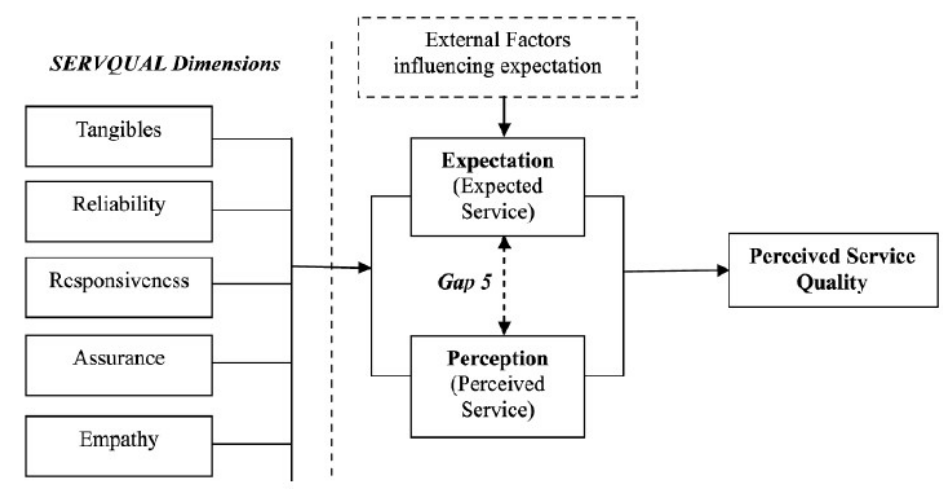

Gambar 4. Pengukuran Kualitas Pelayanan dengan SERVQUAL

Melakukan pengukuran kualitas pelayanan berdasarkan gambar 4 menunjukan bahwa terdapatnya faktor-faktor yang berasal dari luar atau eksternal yang dapat mempengaruhi tingkat harapan dan persepsi pelanggan. Terdapatnya Gap 5 pada gambar tersebut menunjukan bahwa terjadinya perbedaan atau selisih antara harapan pelanggan yang disebut dengan kualitas pelayanan yang diterima (Kumar et al., 2009) [13].

SERVQUAL dapat dilakukan penghitungan dengan rumus sebagai berikut (Arasli, Huseyin, et al. 2005) [14], Skor SERVQUAL = Skor Persepsi - Skor Harapan.

\section{4 e-LOYALTY}

Bentuk sikap pelanggan yang memiliki pontensi dan komitmen untuk melakukan pembelian secara berulang kali dengan mengunjungi website perusahaan atau organisasi baik itu terjadi transaksi online atau tidak digambarkan sebagai bentuk e-Loyalty oleh Srinivasan (2002) [15]. Bentuk e-Loyalty bisa menjadi keuntungan tersendiri bagi para pelaku bisnis karena para pelanggan memiliki komitmen jangka panjang dan mengurangi biaya untuk mencari pelanggan baru seperti yang digambarkan Reichheld et al. (2000) [16]. Selain itu, bentuk e-Loyalty dapat memberikan motivasi atau dorongan kepada para pelanggan baru untuk membeli di tempat langganannya.

\section{Model Penelitian}

Di dalam penelitian ini digunakan metode kajian literatur dengan menggunakan data-data sekunder yang berasal dari kumpulan-kumpulan penelitian pada topik tertentu yang berasal dari jurnal-jurnal, tesis, buku, dokumen, dan sebagainya. Berdasarkan kajian yang didapat sebanyak 20 literatur (dari tahun 2010-2019) yang memiliki topik penelitian yang sesuai dan kemudian disaring kembali untuk melihat mana yang paling revelan. Penelitian ini 
mengangkat topik Penerapan Manajemen Pelanggan Elektronik untuk meningkatkan kepuasan pelanggan di dalam bengkel resmi.

\section{Pembahasan}

Pembahasan kajian literatur ini dimulai dengan penelitian yang dilakukan oleh Idris Bashir Bugaje (2015) [17] yang berjudul "Effect of Electronic Customer Relationship Management (e-CRM) on Business Organisations". Penelitian yang dilakukan oleh Idris ini menggunakan metode Kualitatif yang mengambil dari sumber kedua, seperti artikel jurnal, buku, sumber di internet yang relevant dengan e-CRM dan tantangan organisasi pada saat mengimplementasikan CRM. Kebutuhan penerapan teknologi yang tepat untuk menangani database pelanggan yang semakin banyak tentu sangat diperlukan. Penggunaan e-CRM dipandang oleh pihak manajemen sebagai penerapan teknologi yang tepat untuk mendekatkan diri dengan pelanggan, mempertahankan pelanggan, ataupun mendapatkan pelanggan baru. Kelebihan lainnya dari teknologi e-CRM ini, memungkinkan pelanggan melakukan interaksi dengan perusahaan dari jarak jauh tanpa harus datang ke bengkel resmi secara langsung. Melalui teknologi ini pula, pelanggan dapat mengakses beragam informasi mengenai perusahaan, mengajukan komplain secara langsung ke perusahaan, ataupun membayar atas jasa yang sudah diberikan oleh perusahaan. Tentu saja dalam penerapannya, e-CRM memiliki beberapa tantangan, seperti keamanan. Pelanggan baru maupun lama kerap kurang percaya untuk berbagi mengenai informasi-informasi apa saja yang harus diberikan ke pihak perusahaan. Pencurian dan penyalahgunaan informasi selalu membayangi pikiran para pelanggan untuk berbagi informasi pribadinya meskipun sistem sudah dilengkapi dengan teknologi pengamanan tingkat tinggi sekalipun. Meskipun pelanggan memiliki sikap skeptis terhadap perusahaan, hal ini wajar karena pelanggan tidak ingin sembarangan untuk berbagi informasi yang sifatnya pribadi. Dalam hal ini, perusahaan harus meningkatkan reputasinya dalam menjaga segala macam bentuk informasi agar para pelanggan dapat meningkatkan kepercayaannya dengan perusahaan. Perusahaan juga diharapkan dapat melakukan strategi lain untuk mendapatkan segala macam bentuk informasi pelanggan. Menjaga database pelanggan yang terus membesar membutuhkan usaha yang lebih besar juga bagi perusahaan sehingga memanfaatkan banyak channel lainnya lebih baik ketimbang hanya menggunakan single channel saja.

Setiap manajer di dalam perusahaan atau organisasi yang berbasis pelayanan terhadap pelanggan, harus bisa memanfaatkan teknologi e-CRM. Hal ini perlu dilakukan agar dapat meningkatkan pendapatan dan ROI, loyalitas pelanggan, ataupun mencari keuntungan bagi perusahaan atau organisasi. Menurut penelitian yang dilakukan oleh Seyed Hossein Nikou et al. (2016) [18] yang berjudul "Electronic Customer Relationship Management, Customer Satisfaction, and Customer Loyalty: A Comprehensive Review Study". Di dalam tinjauan pustaka yang dibuat oleh Seyed, disimpulkan bahwa penerapan teknologi e-CRM bisa ditujukan untuk meningkatkan loyalitas pelanggan di era pemasaran digital. Selain itu, pemanfaatan e-CRM memiliki dampak yang positif sehingga dapat menentukan faktor-faktor apa saja yang perlu diperhatikan agar pelanggan dapat meningkat tingkat kepuasannya maupun loyalitasnya. Masih menurut Seyed disebutkan bahwa tingkat kepercayaan masih dijadikan variabel utama untuk menentukan kekuatan hubungan antara e-CRM, kepuasan pelanggan, dan loyalitas pelanggan.

Berdasarkan penelitian yang dilakukan oleh Abdurrahman Saleh (2013) [19] yang berjudul "Dampak Implementasi Sistem CRM Online Terhadap Tingkat Kepuasan Pelanggan: Studi Kasus Dealer Mobil Honda Auto Daya Group" yang bersifat korelatif dengan mengukur tingkat kepuasan pelanggan melalui lima aspek kualitas pelayanan (Reliability, Responsiveness, Assurance, Empathy, dan Tangibles) terhadap sistem manajemen pelanggan elektronik yang diterapkan di bengkel tersebut. Dari 335 responden yang diambil sebagai sampel, didapatkan hasilnya, yakni dimensi Reliability yang ada di dalam sistem menajemen pelanggan elektronik tersebut berpengaruh terhadap tingkat kepuasan pelanggannya sebesar 36\%. Dimensi Responsiveness memiliki pengaruh terhadap tingkat kepuasan pelanggannya sebanyak 38\%. Sedangkan dimensi Assurance berpengaruh sebesar 33\%, dimensi Empathy sebesar 33,8\%, dan Tangibles sebesar 39\%. Hasil pengujian dilanjutkan pada tahapan analisis harapan kinerja didapatkan hasilnya, seperti pada dimensi Reliability terdapat gap atau kesenjangan antara harapan pelanggan dengan apa yang dirasakan pelanggan pada saat itu. Dimensi tersebut berkaitan dengan kinerja sistem pelayanan, tepat dalam menyajikan data yang diperlukan, dan mudah menghubungi bagian pelayanan pelanggan. Di dalam dimensi Responsiveness masih ada gap yang berarti belum memberikan kepuasan kepada pelanggan yang tidak sesuai dengan harapan mereka. Hal ini meliputi kecepatan dalam merespon segala macam keluhan, menyelesaikan keluhan, dan penyajian data. Assurance masih terdapat gap. Pada dimensi ini belum adanya jaminan kepastian terhadap keamanan data informasi pelanggan yang ada di dalam sistem manajemen

ISSN : 2655-139X (ONLINE)

ISSN : 0216-4221 (PRINT) 
pelanggan, keyakinan bengkel melakukan follow up atas keluhan pelanggan, dan ketepatan pemberian solusi bila terjadi keluhan terhadap pelanggan. Ditemukan gap pada dimensi Empathy, meliputi informasi kurang lengkap pada website perusahaan, komunikasi yang rutin dari bengkel ke para pelanggan dalam bentuk service reminder, greetings, dan sebagainya. Selain itu, pelanggan merasa e-newsletter belum dikirim secara rutin ke email pelanggan, serta aktivitas interaksi belum dilaksanakan secara rutin antara dengan pelanggan. Pada dimensi Tangibles ditemukan terdapat kesenjangan, seperti jalur komunikasi yang masih terbatas hanya seputar telepon, sms dan email. Pada tampilan navigasi website perlu dirapihkan, dan keamanan penyimpanan data pelanggan perlu ditingkatkan lebih maksimal. Dari hasil penelitian tersebut, ditarik kesimpulan bahwa seluruh dimensi, seperti Reliability, Responsiveness, Assurance, Empathy dan Tangibles memiliki pengaruh terhadap kepuasan pelanggan di dalam bengkel Dealer Honda Auto Daya Group. Dengan memperbaiki semua dimensi tersebut dapat memberikan dampak yang besar untuk meningkatkan kepuasan pelanggan di dalam bengkel tersebut.

CRM memiliki pengaruh dengan arah yang searah terhadap kepuasan pelanggan. Konsumen dapat memiliki tingkat kepuasan yang tinggi bila perusahaan atau dalam hal ini bengkel resmi menjalankan CRM dengan baik dan optimal. Penelitian yang dilakukan oleh Ellena Nurfazria Handayani dan Edwin Yudha Pratama (2018) [20] yang berjudul "Pengaruh Manajemen Hubungan Pelanggan Terhadap Kepuasan Konsumen" yang merupakan penelitian jenis asosiatif dengan menggunakan pendekatan kuantitatif. Penelitian dilakukan di bengkel resmi mobil Nissan Radin Inten yang mengambil jumlah sampel sebanyak 120 responden. Penelitian ini melihat pengaruh manajemen hubungan pelanggan dengan kepuasan pelanggan yang menitikberatkan kepada tiga variabel, yakni Komitmen, Komunikasi, dan Kualitas Pelayanan yang diberikan. Dari hasil penelitian didapat bahwa variabel manajemen hubungan pelanggan, seperti Komunikasi dengan para pelanggan memiliki pengaruh sebesar 55\%. Artinya variabel tersebut turut memberikan memiliki pengaruh yang nyata terhadap kepuasan pelanggan. Penggunaan CRM terhadap kepuasan pelanggan dilihat dari masing-masing nilai sig. dimensinya dan memiliki angka yang lebih kecil dari $5 \%$ atau $0,000<0,05$. Hal ini menunjukkan bahwa CRM memiliki pengaruh yang nyata terhadap tingkat kepuasan pelanggan.

Penerapan e-CRM terbukti dapat meningkatkan tingkat kepuasan pelanggan. Hal ini dibuktikan oleh penelitian yang dilakukan Enggar Silvia Ariansyah et al. (2014) [21] dengan judul "Desain Dan Implementasi Pada Customer Care Service Mobil PT Astra Daihatsu Malang". Penelitian dilakukan di PT Astra Daihatsu Malang menggunakan metode kualitatif. Dari hasil penyebaran angket mengenai kepuasan pelanggan, jumlah pelanggan yang puas menurun bahkan cenderung mengeluh dari hasil proses service yang diberikan. Hal ini disebabkan tidak adanya sebuah sistem otomatis sebagai pengingat atau konfirmasi ke pelanggan bahwa kendaraan sudah selesai dilakukan perbaikan dan petugas service tidak melakukan konfirmasi langsung kepada pelanggan. Proses service yang diberikan oleh PT Astra Daihatsu, meliputi service terhadap kendaraan dan pelanggan. Untuk service kendaraan dilakukan oleh tenaga mekanik dan service pelanggan meliputi ruang tunggu, lama atau tidaknya proses service, serta pelayanan yang ramah dari para petugas service. Sebelum dibuat sebuah sistem otomatis yang berbasis SMS gateway. Sistem ini digunakan oleh tiga user dengan hak akses yang berbeda-beda, yakni Service Advisor (SA), bagian sparepart, dan mekanik. Sistem tersebut akan otomatis memberikan informasi kepada para pelanggan mengenai status kendaraan yang sedang diperbaiki via SMS tanpa harus pelanggan menelpon terlebih dahulu ke bengkel. Dari hasil pengembangan sistem eCRM tersebut, dilakukan kembali analisa mengenai tingkat kepuasan para pelanggan yang sudah menggunakan sistem tersebut. Hasilnya adalah tingkat kepuasan pelanggan meningkat menjadi $70 \%$.

Penelitian Eko K. Budiardjo dan Heryudi Ganesha (2010) [22] yang berjudul "Penyusunan Fitur Mobile CRM melalui Pemodelan Organisasi dengan Metoda Soft System Methodology: Studi Kasus Bengkel Otomotif" bertujuan untuk mencari fitur apa saja yang diperlukan dalam membuat sebuah mobile CRM pada bengkel mobil. Metode penelitian yang digunakan adalah dengan Soft System Methodology atau SSM. Ada tujuh tahapan yang dilalui dengan menggunakan SSM, yakni: 1. Menganalisa situasi permasalahan yang beragam, 2 . Mengidentifikasi situasi permasalahan, 3. Mendefinisikan akar permasalahan dengan sistem yang relevan dengan menggunakan analisis CATWOE, 4. Konsep pemodelan yang akan digunakan, 5. Membandingkan pemodelan dengan situasi yang nyata, 6. Diskusikan atau melakukan perubahan, 7. Mengambil tindakan. Di dalam penerapan Soft System Methodology (SSM), diperoleh pemetaan yang melibatkan tujuh bagian penting yang ada di dalam bengkel yang disebut sebagai stakeholder atau pemangku kepentingan, seperti pelanggan, service advisor, mekanik, supervisor mekanik, manajer bengkel, staf gudang suku cadang, dan kasir. Hasil analisa CATWOE menjelaskan ada beberapa sistem yang dapat digunakan oleh perusahaan, seperti penyimpanan data pelanggan ke

ISSN : 2655-139X (ONLINE)

ISSN : 0216-4221 (PRINT) 
dalam sistem bengkel secara manual oleh bagian service advisor, atau secara otomatis yang diisikan langsung oleh pelanggan melalui media inputan yang lain. Sistem bengkel digunakan oleh penyelia mekanik untuk menyampaikan informasi ke pelanggan yang dilakukan oleh bagian service advisor, dan sistem-sistem lainnya yang dapat dimanfaatkan perusahaan untuk meningkatkan kualitas pelayanan. Hasil CATWOE tersebut juga berhasil mempetakan aktor-aktor yang memiliki peran penting di dalam penggunaan CRM, seperti Manajer Bengkel, Service Advisor, Penyelia Mekanik, Mekanik, Staf Gudang. Dari hasil analisa tersebut, terlihat perspektif dari sebuah sistem baik dari sisi internal maupun eksternal. Hal ini dapat memudahkan untuk melakukan pengembangan sebuah sistem dengan melihat berbagai perspektif. Hadirnya penerapan CRM di dalam organisasi atau perusahaan diharapkan dapat mengubah strategi organisasi berpusat kepada pelanggan. Dengan berubahnya strategi, organisasi atau perusahaan dapat mendekatkan diri dengan para pelanggannya dan dibutuhkan konsistensi yang berasal dari level operasional hingga jajaran top management.

Hadi Zakaria dan Aida Eka Marlia (2019) [23] melakukan penelitian mengenai "Perancangan Sistem Informasi Customer Relationship Management (CRM) untuk Meningkatkan Loyalitas dan Pelayanan Customer Berbasis Web dengan Model Waterfall". Penelitian ini bersifat kualitatif dan deskriptif yang dilakukan di bengkel resmi milik Mitsubishi, PT. Srikandi Diamond Motors. Hasil analisa berdasarkan CRM yang sudah berjalan terdapat kekurangan pada sistem pendaftaran service hingga selesai, dimana sistem belum terintegrasi antardepartemen, seperti data pelanggan, stok suku cadang, estimasi biaya perbaikan, data penyalur suku cadang. Selain itu, sistem yang digunakan oleh pelanggan untuk booking jadwal service masih konvensional menggunakan saluran telepon maupun datang langsung ke tempat. Alhasil antrian untuk pelayanan perbaikan menjadi menumpuk pada bagian customer service. Hasil analisa tersebut dijadikan penelitan untuk dilakukan pengembangan pada bagian sistem informasi CRM yang menggunakan model Waterfall. Model ini digunakan untuk mengembangkan perangkat lunak yang sudah ada menjadi lebih tersusun dan berurutan dari tingkat analisis, desain, pembuatan program hingga pengujian. Sebagai solusi terhadap permasalahan tersebut, disusunlah basis data baru yang menggunakan Entity Relationship Diagram (ERD). Setelah itu, barulah dibentuk sebuah sistem CRM baru agar dapat terintegrasi semua data yang diperlukan di dalam bengkel. Hasil akhirnya dari pembuatan CRM baru tersebut, sudah terintegrasi semua data yang diperlukan agar dapat meningkatkan kualitas pelayanan terhadap pelanggan.

Berdasarkan hasil penelitian yang dilakukan oleh Benny Martha Dinata et al. (2016) [24] yang berjudul "Penerapan Teknologi Informasi dan Customer Relationship Management Sebagai Keunggulan Bersaing Berkelanjutan Guna Meningkatkan Kinerja Perusahaan" menyebutkan bahwa penerapan teknologi informasi akan memiliki dampak yang baik dan nyata terhadap kinerja perusahaan, baik secara langsung maupun tidak langsung. Penelitian ini menggunakan metode kuantitatif dan dilakukan di bengkel resmi Toyota, Nasmoco area Jawa Tengah dan Yogyakarta. Analisa data dilakukan dengan menggunakan metode Structural Equation Model (SEM). Tipe SEM yang digunakan berdasarkan varian atau Partial Least Square (PLS). Ada empat variabel yang diambil pada penelitian ini, yakni: Teknologi Informasi, Customer Relation Management, Keunggulan Bersaing Berkelanjutan, Kinerja Perusahaan. Hasil analisa dari penelitian ini menunjukan bahwa Teknologi Informasi berpengaruh positif dan signifikan terhadap keunggulan bersaing berkelanjutan. Hal ini menginformasikan bahwa perusahaan harus membuat sebuah sistem yang dapat diakses ataupun digunakan dengan mudah oleh pelanggan. Meningkatkan kecepatan bandwith jaringan untuk memberikan kecepatan pengaksesan data pelanggan perlu dilakukan. Penerapan teknologi informasi ini diimplementasikan ke dalam Nasmoco Integrated System (NIS). Hasil analisa berikutnya menunjukan bahwa Teknologi Informasi memiliki pengaruh yang positif bagi kinerja perusahaan. Hal ini berarti teknologi informasi yang ada di dalam bengkel merupakan bagian integrasi dari beberapa proses bisnis yang utuh. Tujuannya ialah untuk meningkatkan kepuasan pelanggan, mulai dari pencatatan kegiatan service, data pelanggan, hingga mengingatkan kembali untuk dilakukan service berikutnya yang mengandalkan teknologi informasi. Customer Relationship Management memiliki pengaruh positif terhadap keunggulan bersaing berkelanjutan. Terjadinya peningkatan kinerja CRM akan memberikan dampak yang positif bagi perusahaan, pelanggan pun akan semakin dekat dengan perusahaan. Peningkatan pelayanan yang baik juga akan membuat pelanggan akan merekomendasikan perusahaan ke teman-teman sejawat, keluarga, bahkan orang lain. Selain itu, CRM yang memiliki pengaruh positif terhadap kinerja perusahaan dimana akan memberikan kemudahan bagi pelanggan untuk berkomunikasi secara aktif dan langsung dengan perusahaan. Bila pelanggan puas, maka akan terjadi peningkatan pada sisi loyalitas mereka. Hal ini sangat penting bagi perusahaan yang berorientasi terhadap pelanggan, karena dengan pelanggan yang loyal maka akan memberikan rekomendasikan ke banyak orang tanpa harus diminta oleh perusahaan. Semakin banyak jumlah pelanggan maka akan memberikan nilai positif bagi kinerja perusahaan. Keunggulan bersaing berkelanjutan memberikan pengaruh kepada kinerja

ISSN : 2655-139X (ONLINE)

ISSN : 0216-4221 (PRINT) 
perusahaan. Semangat untuk melakukan perubahan akan memberikan dapat yang baik bagi perusahaan agar dapat bersaing dengan para kompetitor. Dengan kinerja perusahaan yang semakin baik, akan memberikan ketahanan terhadap keberadaan perusahaan. Dari semua variabel yang diukur, dapat ditarik sebagai kesimpulan bahwa penggunaan CRM di dalam perusahaan memberikan pengaruh yang positif baik terhadap kinerja perusahaan baik langsung maupun tidak langsung.

Nina Wachyu Ningsih, et al. (2016) [25] melakukan penelitian dengan judul "Pengaruh Customer Relationship Management (CRM) Terhadap Kepuasan dan Loyalitas Pelanggan” yang dilakukan di AUTO 2000 Cabang Denpasar. Penelitian ini dilakukan dengan metode kuantitatif dengan mengambil sample sebanyak 113 orang. Dasar penelitian ini untuk menunjukan hubungan antara customer relationship management dengan kepuasan pelanggan. Penerapan CRM sekecil apapun dapat memberikan dampak yang positif dalam meningkatkan loyalitas pelanggan. Penggunaan CRM diterapkan pada pelayanan purna jual untuk pelanggan, meliputi: perawatan berkala cepat (express maintenance), perawatan berkala (regular check), perbaikan umum (general repair), THS (Toyota Home Service), dan booking service. Pelayanan purna jual secara tidak langsung mengikat para pelanggan untuk berinteraksi dengan perusahaan, dan mempertahankan tingkat loyalitas mereka dengan menggunakan jasa yang ada di AUTO2000. Hasil penelitian menunjukan bahwa penerapan CRM yang ada di dalam perusahaan ini, memberikan kontribusi sebesar $40,70 \%$ terhadap tingkat Kepuasan Pelanggan. Dengan demikian, dapat disimpulkan bahwa apabila CRM terus dioptimalkan dapat meningkatkan Kepuasan Pelanggan. Dampak dari Kepuasan Pelanggan tersebut meningkatkan sisi Loyalitas Pelanggan yang signifikan sebesar 17,50\%. Hal ini menunjukkan Kepuasan Pelanggan terbukti mempengaruhi tingkat Loyalitas Pelanggan.

Menurut penelitian yang dilakukan oleh Rizqa Janati Adnin et al. (2013) [26] yang berjudul "Pengaruh Customer Relationship Management Terhadap Loyalitas Pelanggan PT Nasmoco Pemuda Semarang", menunjukan bahwa penggunaan CRM memiliki pengaruh positif terhadap tingkat Loyalitas Pelanggan. Penelitian yang dilakukan menggunakan metode Explanatory atau penjelasan ini, mengambil sampel dari pelanggan PT Nasmoco Pemuda Semarang yang sudah berlangganan lebih dari satu bulan. Penentuan sampel dilakukan dengan menggunakan accidental sampling. Penelitian ini dibagi ke dalam tiga komponen utama yang ada di CRM, yakni Sumber Daya Manusia (People), Proses (Process), dan Teknologi (Technology). Dari hasil penelitian menunjukan bahwa terdapat pengaruh yang signifkan antara Sumber Daya Manusia dengan Loyalitas Pelanggan sebesar 23\%. Sedangkan proses memiliki dampak positif yang cukup signifikan terhadap Loyalitas Pelanggan sebesar 44,8\%. Pada bagian Teknologi memberikan dampak yang positif juga walaupun hanya sebesar 26,4\%. Dampak CRM terhadap tiga komponen utama tersebut memiliki pengaruh yang sigfinikan yakni $46 \%$. Dengan demikian, dapat disimpulkan bahwa Loyalitas Pelanggan yang ada di PT Nasmoco Pemuda Semarang dipengaruhi oleh penggunaan CRM sebesar 46\% dan sisanya 54\% dipengaruhi oleh faktor selain SDM, Proses, maupun Teknologi, seperti Kualitas Pelayanan, Kualitas Produk, Nilai Merek, Harga, Promosi, dan lain sebagainya.

Penelitian Mingruedee Mettagarunagul dan Pensiri Puengprakiet (2011) [27] yang berjudul "The Use of eCRM to Enhance Customer Relationship: The Case of Toyota Mahanakkorn" yang dilakukan dengan metode kualitatif ini menjelaskan penggunaan e-CRM di dalam Toyota Mahanakorn, Thailand. Mingruedee melakukan penelitian untuk mencari menggali sejauh mana penerapan e-CRM di dalam Toyota Mahanakorn. Toyota Mahanakorn menggunakan e-CRM sebagai alat atau tool untuk berhubungan dengan para pelanggannya. Penelitian ini ditujukan untuk mencari faktor penting apa saja yang dapat mempengaruhi kepuasan pelanggan dan apa saja yang perlu diperhatikan oleh organisasi atau perusahaan terhadap kehadiran e-CRM. Penelitian dimulai dengan melakukan wawancara kepada para petinggi dealer Toyota terbesar di Bangkok, Thailand tersebut. Pihak yang diwawancarai memiliki posisi penting, seperti Vice President, Customer Relationship Manager, Showroom Manager, Senior IT Manager, dan bagian Customer Service Advisor Manager. Dari wawancara tersebut, peneliti mencari informasi lebih jauh mengenai perananan e-CRM di dalam perusahaan tersebut. Toyota Mahanakorn membagi e-CRM menjadi 3 (tiga) bagian penting, seperti manajemen, pegawai, dan pelanggan. Dari sisi teknologi, Toyota Mahanakorn menggunakan e-CRM untuk melakukan komunikasi dengan para pelanggannya melalui saluran website dan sistem mobile. Sebelum menggunakan e-CRM, Toyota Mahanakorn mengandalkan saluran komunikasi model lama, seperti call center dan showroom yang dimiliki oleh perusahaan. Dengan mengandalkan saluran komunikasi baru, yakni website dan mobile diharapkan dapat menjangkau para pelanggan Toyota Mahanakorn selama 24 jam penuh. Kehadiran teknologi e-CRM yang ada di dalam perusahaan, memudahkan semua pegawai di berbagai departemen (departemen penjualan, departemen bengkel resmi, departemen hubungan pelanggan) yang ada di dalam perusahaan untuk mencari informasi detail pelanggan dengan

ISSN : 2655-139X (ONLINE)

ISSN : 0216-4221 (PRINT) 
cepat dan mudah, seperti jenis kendaraan, jejak rekam kapan terakhir kali ke bengkel, pemeriksaan berkala, booking jadwal ke bengkel, dan sebagainya.

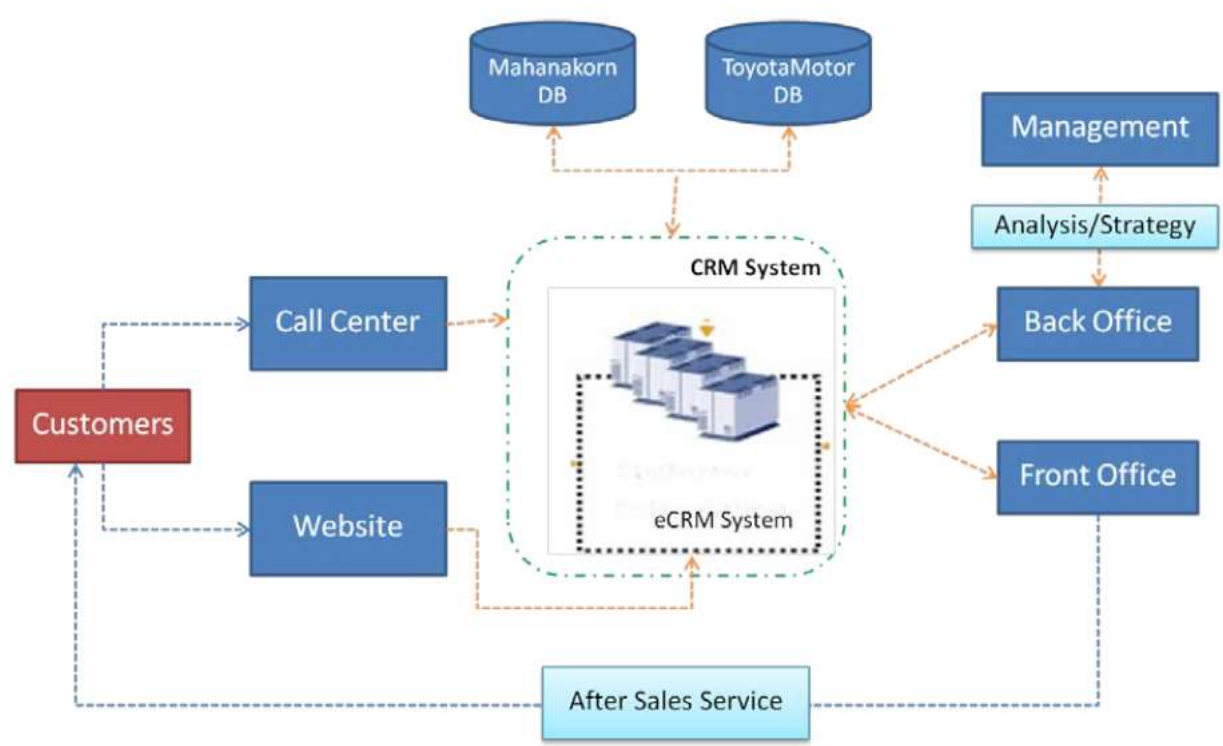

Gambar 5. Proses e-CRM di Toyota Mahanakorn

\section{Kesimpulan}

Penerapan teknologi Manajemen Pelanggan atau CRM di dalam perusahaan sangat bermanfaat untuk menangani jumlah database pelanggan yang terus bertambah. Hadirnya teknologi internet memberikan perubahan dampak yang positif bagi perusahaan atau organisasi untuk mengembangkan CRM menjadi lebih luas lagi, yakni Manajemen Pelanggan secara Elektronik atau e-CRM. Penerapan e-CRM menjadi sebuah pondasi untuk menjalankan strategi bisnis agar mendapatkan keuntungan, menjaga loyalitas pelanggan, mendapatkan pelanggan baru hingga menjadi media atau tools komunikasi yang tepat guna untuk menjangkau pelanggan yang berada di seluruh dunia.

Dukungan terhadap e-CRM sangat diperlukan mulai dari jajaran operasional hingga level top management agar strategi bisnis yang dijalankan berbanding lurus dengan tujuan penerapan sistem manajemen pelanggan yang ada di dalam perusahaan. Di dalam pembuatan e-CRM, dilakukan analisa yang diambil dari berbagai sudut pandang, mulai dari internal hingga eksternal. Hal ini perlu dilakukan agar sistem dapat dikembangkan lebih mudah di masa mendatang.

Perbaikan demi perbaikan dalam pelayanan kepada pelanggan perlu dilakukan dan ditingkatkan. Kelima dimensi kualitas pelayanan, seperti Reliability, Responsiveness, Assurance, Empathy, dan Tangibles perlu dilakukan evaluasi secara berkala untuk dapat meningkatkan kepuasan pelanggan. Tujuan akhir dari penerapan eCRM ini adalah untuk meningkatkan kualitas pelayanan agar sesuai dengan harapan para pelanggan. Bila pelanggan puas maka akan memiliki loyalitas yang tinggi kepada organisasi atau perusahaan atau disebut dengan e-Loyalty. Bentuk dari e-Loyalty, pelanggan akan mengunjungi website atau aplikasi perusahan berulang kali baik terdapat transaksi atau tidak. Selain itu, bila pelanggan puas akan mengajak ataupun menyebarkan hal yang positif mengenai perusahaan kepada para sanak famili ataupun kerabat yang akan memberikan keuntungan tersendiri bagi perusahaan seperti mendapatkan pelanggan baru tanpa harus mengeluarkan biaya tambahan.

\section{Referensi}

1. Chaffey, Dave. 2009. E-Business and E-Commerce Management (4 $4^{\text {th }}$ Edition ed.). Inggris: Pearson Education.

2. Tempo.co. (2019, 18 Maret). Februari 2019 Penjualan Motor 1,1 Juta Unit, Tumbuh 19,4 Persen. Diakses pada 1 Oktober 2019, dari https://otomotif.tempo.co/read/1 186578/februari-2019-penjualan-motor-11-juta-unit-tumbuh-194-persen 
3. Cnnindonesia.com. (2019, 28 September). Penjualan Mobil Januari-Agustus 2019 Tembus 660 Ribu. Diakses pada 1 Oktober 2019, dari https://www.cnnindonesia.com/teknologi/20190927210819-384-434822/penjualan-mobil-januariagustus-2019-tembus-660-ribu

4. Jdpower.com. (2018, 29 Agustus). Mitsubishi Meraih Peringkat Tertinggi dalam Kepuasan Pelanggan Untuk Layanan Pasca Penjualan. Diakses pada 6 Oktober 2019, dari https://japan.jdpower.com/press-releases/2018-indonesia-customerservice-index-mass-market-study-0

5. Wijayanti, Teti dan Imam Azhari. 2011. Pengembangan Customer Relationship Management Berbasis Web pada Griya Muslim Flora. Jurnal Sistem Informasi Indonesia (JUSI). 1(1): 13-20.

6. Paul, G., \&Jonbok, B. 2001. Customer Relationship Management. Retrieved from http://escholarship.org/uc/item/76n7d23

7. Kalakota, R dan Robinson, M. 2001. E-Business 2.0 Roadmap for Success. Massachusetts: Addison Wesley Longman Inc.

8. Francis, Buttle. 2007. Customer Relationship Management (Manajemen Hubungan Pelanggan): Concept and Tools. Malang: Banyu Media.

9. Ab Hamid, N. \& McGrath, G. 2005. The Diffusion of internet activity on retail web sites : A Customer relationship model. Communication of the IIMA, 5(2): 35-46.

10. Turban, et al. 2004. Electronic Commerce: A Managerial Perspective. New Jersey: Prentice Hall.

11. Pratiwi, Umi. 2010. Balance Scorecard dan Manajemen Strategik. Jurnal Ilmiah 11 (2): 166-167.

12. Zeithaml, V.A. \& Bitner, M.J. 2003. Services Marketing: Integrating Customer Focus Across The Firm. New York: McGraw Hill.

13. Kumar, M., Kee, F. T. \& Manshor, A. T. 2009. Determining the relative importance of critical factors in delivering service quality of banks; An application of dominance analysis in SERVQUAL model. Managing Service Quality. 19(2): 211-228.

14. Arasli, H, Turan Katrircioglu, S., Mehtap-Smadi, S. 2005. A comparison of service quality in the banking industry: Some evidence from Turkish - and Greek - speaking areas in Cyprus. International Journal of Bank Marketing. 23 (7): 508-526.

15. Srinivasan, S.S., Anderson, R., Ponnavolu, K., 2002. Customer loyalty in e-commerce: an exploration of its antecedents and consequences. Journal of Retailing. 78 (1): 41-50.

16. Reichheld, F.F., Markey, R.G., Hopton, C. 2000. E-customer loyalty-applying the traditional rules of business for online success. European Business Journal. 12 (4): 173-180.

17. Bugaje, Idris Bashir. 2015. Effect of Electronic-Customer Relationship Management (e-CRM) on Business Organisations. Abuja Journal of Business and Management. 1(1): 73-80.

18. Nikou, Seyed Hossein et al. 2016. Electronic Customer Relationship Management, Customer Satisfaction, and Customer Loyalty: A Comprehensive Review Study. International journal of Management and Economics Invention. 2(12): 11331144.

19. Saleh, Abdurrahman. 2013. Dampak Implementasi Sistem CRM Online Terhadap Tingkat Kepuasan Pelanggan: Studi Kasus Dealer Mobil Honda Auto Daya Group. Tesis. Jakarta: Universitas Bina Nusantara.

20. Handayani, Ellena Nurfazria \& Edwin Yudha Pratama. 2018. Pengaruh Manajemen Hubungan Pelanggan Terhadap Kepuasan Konsumen. Jurnal Manajemen Bisnis Krisnadwipayana.

21. Ariansyah, Enggar Silvia, Banni S. A., dan Liduina A. P. 2014. Desain Dan Implementasi Pada Customer Care Service Mobil Pt Astra Daihatsu Malang. Jurnal Dinamika DotCom. 6(2)

22. Budiardjo, Eko K. dan Heryudi Ganesha. 2010. Penyusunan Fitur Mobile Crm Melalui Pemodelan Organisasi Dengan Metoda Soft System Methodology: Studi Kasus Bengkel Otomotif. Jurnal Seminar Internasional Informatika. 1(5): 370379.

23. Zakaria, Hadi dan Aida Eka Marlia. 2019. Perancangan Sistem Informasi Customer Relationship Management (CRM) untuk Meningkatkan Loyalitas dan Pelayanan Customers Berbasis Web dengan Model Waterfall. Jurnal Teknologi Sistem Informasi dan Aplikasi. 2(2): 66-72.

24. Dinata, Benny Martha, Sugeng Wahyudi, dan Ahyar Yuniawan. 2016. Penerapan Teknologi Informasi Dan Customer Relationship Management Sebagai Keunggulan Bersaing Berkelanjutan Guna Meningkatkan Kinerja Perusahaan (Studi pada Bengkel Resmi Toyota Jawa Tengah dan Jogja). Jurnal Bisnis Strategi. 25(1): 1-15

25. Ningsih, Nina Wachyu, Suharyono dan Edy Yulianto. 2016. Pengaruh Customer Relationship Management (Crm) Terhadap Kepuasan Dan Loyalitas Pelanggan (Survei pada Pelanggan PT Astra Internasional, Tbk-TSO AUTO2000 Cabang Denpasar). Jurnal Administrasi Bisnis. 30(1): 171-177.

26. Adnin, Rizqa Janati, Nawazirul Lubis dan Widayanto. 2013. Pengaruh Customer Relationship Management Terhadap Loyalitas Pelanggan Pt. Nasmoco Pemuda Semarang. Diponegoro Journal of Social and Politic Science.

27. Mettagarunagul, Mingruedee, dan Pensiri Puengprakiet. 2011. The Use of eCRM to Enhance Customer Relationship: The Case of Toyota Mahanakkorn. Tesis. Swedia: Mälardalen University. 